\title{
Conclusiones
}

\section{Mesa redonda sobre la procesionaria del pino}

Celebrada durante la III Reunión de Sanidad Forestal de la Sociedad Española de Ciencias Forestales, el día 7 de octubre de 2015 en la ETSI Montes, Forestal y del Medio Natural

de la Universidad Politécnica de Madrid

\section{Contexto, asistentes y ponentes}

Con motivo de la celebración de la III Reunión de Sanidad Forestal, y como resultado de la creciente demanda por parte diferentes sectores de un foro de debate sobre la gestión de la procesionaria del pino en nuestro país, se celebró una mesa redonda dedicada en exclusiva a esta problemática.

A la mesa redonda asistieron unos 85 profesionales del sector de la Sanidad Forestal en España, representando a 16 universidades, 9 centros de investigación, 13 instituciones de la administración pública y 9 empresas del sector.

La mesa redonda fue coordinada por Gerardo Sánchez Peña (Servicio de Sanidad Forestal y Equilibrios Biológicos, Ministerio de Agricultura, Alimentación y Medio Ambiente), y participaron como ponentes Francisco Javier Blasco Fernández (D.G. Medio Ambiente, Comunidad de Madrid), Jesús Alberto Del Río Lopez (Asociación Forestal de Valladolid), José Antonio Hódar Correa (Departamento de Ecología, Universidad de Granada), y Luis Núñez Vázquez (Servei de Sanitat Forestal. Conselleria Medi Ambient, Agricultura i Pesca, Govern de les Illes Balears). 


\section{Conclusiones consensuadas entre los ponentes de la mesa}

La procesionaria del pino supone hoy en día un grave problema generalizado y recurrente.

$\mathrm{Su}$ impacto negativo repercute en la producción de madera, mediatiza fuertemente el aprovechamiento (piñón, recogida de setas, caza, actividades al aire libre) y la salud de personas y animales que se encuentran expuestos a su acción.

Por su carácter endémico y su imbricación con los pinares autóctonos peninsulares no está claro que pueda considerarse una plaga forestal sensu stricto. Sin embargo el nivel de daños que produce, y su impacto puntual en la salud, unido a que su origen son los bosques de pinar, hace que sea necesario su manejo en este ámbito.

La procesionaria y el pinar autóctono en general conviven perfectamente sin que haya grave merma en la vitalidad forestal. Sin embargo en los últimos 50 años la situación ha cambiado radicalmente por el cambio del medio: en España de las 4,4 millones de hectáreas cubiertas actualmente por pino, 2 millones corresponden a nuevas repoblaciones; en Francia de los 3 millones existentes 1,9 son repoblados y en Italia de 0,65 millones existentes 0,25 son artificiales. Todas estas nuevas masas tienen en común el ser artificiales, coetáneas, monoespecíficas y regulares. En dichas situaciones la procesionaria es susceptible de convertirse en una grave plaga recurrente, ante la cual el bosque no se encuentra adaptado, pudiendo considerarse una especie exótica e invasora.

Situaciones similares ocurren en las zonas donde la procesionaria y el pino no han coevolucionado: son los casos de localizaciones insulares, pinares de alta montaña, y pinares en latitudes al norte del área circunmediterránea, donde los condicionantes del medio han limitado hasta ahora el contacto. Los recientes y esperados cambios en el clima y la globalización del transporte están rompiendo este aislamiento. Este tipo de situaciones pueden requerir de soluciones diferentes a las aplicables en la zona endémica de distribución de la procesionaria, con el fin de evitar su asentamiento.

Es necesario implementar de forma continuada estrategias de convivencia con la procesionaria: la superficie ocupada por los pinares, la fuerte imbricación procesionaria-pino, el uso productivo y el cada vez más intenso uso social y recreativo que se hace de los espacios forestales implica que sea imprescindible intervenir.

El fin último a conseguir para minimizar el impacto de la procesionaria pasa por la naturalización de las repoblaciones forestales: deben aclararse las masas, fomentar la irregularidad en edades y su conversión en bosques mixtos. Bajo este escenario el impacto de la procesionaria es mucho menor y el proceso de convivencia sin intervención fitosanitaria puede producirse perfectamente. Este es un proceso largo, que en función de la edad actual de las repoblaciones puede durar un mínimo de 40 años de intervenciones selvícolas progresivas y continuadas.

Durante este periodo de conversión resulta imprescindible en el marco de un Plan de manejo integrado el seguimiento continuado de la procesionaria y el diseño de actuaciones puntuales de control, restringidas únicamente a cuando el nivel de daños 
y el impacto sobre la sociedad lo hagan imprescindible. Esto supone que son necesarias:

- Herramientas de seguimiento y monitoreo de poblaciones (trampas de feromonas principalmente).

- Herramientas de manejo puntual adecuadas a las situaciones particulares: - Inyecciones y corta de bolsones en árboles individuales y aislados.

- tratamientos terrestres en bordes donde la red viaria lo permita.

- Tratamientos aéreos cuando las zonas a cubrir tengan un gran tamaño o sean no accesibles por maquinaria terrestre.

- Uso de insecticidas de origen biológicos, piretroides o antiquitinizantes en función del medio a tratar y de la recurrencia esperada de los ataques.

- Búsqueda de nuevas herramientas de predicción que ayuden a la toma de decisiones, y de actuación que complementen o sustituyan a las presentes.

El objetivo final es la reconversión del pinar en una estructura donde la procesionaria vuelva a ser un componente del medio, y no una plaga exótica del sistema forestal, excepto en los sistemas donde actualmente no es autóctona. Este objetivo se ve en la actualidad comprometido por una situación normativa restrictiva, que limita el uso de las herramientas de gestión necesarias. Monitoreo y trabajos selvícolas han de ser los pilares de un plan de manejo, a la vez que herramientas principales, acompañadas por herramientas secundarias (tratamientos) de forma puntual cuando sea necesario. 
